\title{
A semelhança da música com a linguagem segundo Theodor Adorno: sentidos diferentes do conceito a partir da música tradicional e da nova música
}

\author{
The similarity of music with language according to Theodor Adorno: \\ different meanings of the concept based on traditional music and \\ new music
}

LUIS FILIPE DE LIMA ANDRADE

filipeee3@gmail.com

(Universidade Federal de Minas Gerais, Minas Gerais, Brasil)

\begin{abstract}
Resumo: Este artigo investiga a concepção de semelhança da música com a linguagem na estética musical de Adorno. Partindo de uma descrição e fundamentação histórica do conceito, o objetivo principal deste artigo consiste na defesa de que o conceito se concebe de modo especifico na música tradicional (tonalidade), por um lado, e na nova música, por outro lado. Desse modo, argumentaremos que, apesar de a nova música ter se rebelado contra o conceito, ele permaneceria presente em sua estrutura, pois, ao fim, ele seria condição para a constituição de um elemento fundamental da música, a saber, o nexo de sentido.
\end{abstract}

Palavras-chave: Adorno; música tradicional; nova música; nexo de sentido; semelhança.
Abstract: This article investigates the conception of similarity between music and language in Adorno's musical aesthetics. Starting with a description and historical grounding of the concept, the main objective of this article is to defend that the concept is conceived in a specific way in traditional music (tonal system), on the one hand, and in new music, on the other hand. Therefore, we will argue that although the new music has rebelled against the concept, it would remain present in its structure, because, in the final analysis, it is a condition for the constitution of a fundamental element of music, namely, the complex of meaning.

Keywords: Adorno; traditional music; new music; complex of meaning; similarity.

\section{Introdução}

A questão do entrelaçamento possível ou efetivo entre as artes foi avaliado amplamente e de diversos modos por Adorno ao longo de seus escritos, de modo que poderíamos dizer que se o filósofo durante um determinado período de sua produção o concebeu de modo negativo - sobretudo a partir da sua caracterização

\footnotetext{
*Agradeço ao Conselho Nacional de Desenvolvimento Científico e Tecnológico (CNPq) pelo financiamento da pesquisa e à disciplina "Modos de Presença nos Fenômenos Estéticos", ministrada pelo Prof. Dr. Rodrigo Duarte (UFMG) no semestre 2020/2 no Programa de Pós-Graduação em Filosofia da UFMG, pois foi neste contexto que surgiram os primeiros insights e reflexões que possibilitaram a realização da pesquisa que resultou na escrita deste artigo.
} 
como pseudomorfose ${ }^{1}$-, é possível notar, por outro lado, que tal posição não foi, de modo algum, rígida e invariável, mas sim reelaborada pelo filósofo em momentos posteriores de sua obra, onde ao menos em alguns destes tal entrelaçamento passaria a ser considerado de outra maneira. No âmbito da música, seria o caso da semelhança desta com a linguagem (Sprachähnlickeit), por exemplo.

A semelhança da música com a linguagem, que pressupõe ao mesmo tempo a diferenciação entre ambas - como Philip Hogh destacou (cf. 2020, p. 75) -, não se constituiu de maneira arbitrária, mas em função de razões históricas e sociais ou, mais especificamente, no processo de crescente racionalização do ocidente do qual a obra musical participa ao seu modo, juntamente - e em contraste - com os elementos miméticos que permanecem subjacentes em sua estrutura. Além disso, a semelhança da música com a linguagem aponta para um elemento fundamental da música, a saber, para a instauração de uma estrutura ou um nexo de sentido (Sinnzusammenhang) ${ }^{2}$, que seria, desde a perspectiva musical, condição não somente para a instituição da validade (Geltung) e do sentido (Sinn) da obra, mas também para a constituição de seu teor de verdade (Warheitsgehalt) e sua consistência (Stimmigkeit), sendo esta última "condição necessária de toda obra musical” (Kreis, 2009, p. 88). O nexo de sentido, desse modo, pode ser concebido como condição da obra musical se constituir enquanto tal, isto é, como obra de arte bem-sucedida (gelungenes Kunstwerk).

Apesar disso, constata-se historicamente que a nova música ${ }^{3}$, em sua atitude de crítica perante a música tradicional, posiciona-se de modo contrário à semelhança da música com a linguagem, na medida em que esta seria, de acordo com os compositores da Segunda Escola de Viena, resquícios da tonalidade que deveriam ser abolidos como um todo. Esta atitude, por sua vez, colocaria inevitavelmente algumas questões. Em primeiro lugar, questionamos se, apesar de tal intenção, a nova música teria de fato conseguido abolir a semelhança da música com a linguagem. Além disso, questionamos quais seriam os impactos da dissolução da semelhança da música com

1 Para uma abordagem detalhada sobre este conceito em Adorno: cf. Duarte, 2014, pp. 237-254.

20 nexo ou estrutura de sentido (Sinnzusammenhang) seria um aspecto estrutural e, portanto, necessário à constituição da obra musical, que seria intrinsecamente relacionado à semelhança da música com a linguagem. No que se refere especificamente ao seu significado, compreendemos que Adorno o teria empregado em sentido próximo daquele que fora definido por Max Weber. Em uma nota de tradução da obra Economy and Society de Max Weber, é afirmado que este conceito: "Referese a uma pluralidade de elementos que formam um todo coerente no nível do significado. Existem vários modos possíveis de relação significativa entre tais elementos, tais como consistência lógica, a harmonia estética de um estilo ou a adequação dos meios para um fim" (Weber, 1978, p. 58). Desde a perspectiva da estética musical adorniana, por sua vez, pode-se dizer que o conceito se refere fundamentalmente à organização da obra através da dialética entre totalidade e particularidade que, em última análise, constitui a obra musical como unidade dotada de sentido.

3 Tendo em vista que a nova música é um conceito amplo que diz respeito a uma diversidade de práticas e procedimentos composicionais e estilísticos, vale a pena assinalar que as menções à nova música neste artigo se referem especificamente à Segunda Escola de Viena, que foi representada sobretudo pelos compositores Arnold Schoenberg (1874 - 1951), Alban Berg (1885 - 1935) e Anton Webern (1883 - 1945). 
a linguagem para a própria música, supondo-se que tal intenção fosse bem-sucedida. Uma música absolutamente despojada de sua semelhança com a linguagem pode constituir-se enquanto tal? Como - e se - seria possível conceber uma composição musical baseada na concepção de nexo de sentido sem fazer referência à semelhança da música com a linguagem?

Tomando tais questões como ponto de partida, o objetivo central deste artigo consiste em apresentar uma proposta de interpretação, a saber, que a nova música, apesar de seu empreendimento crítico contra a sua semelhança com a linguagem, não conseguiria aboli-la por definitivo, mas a manteria de algum modo, dado que ela seria condição de estruturação da obra musical. No entanto, argumentaremos que a manutenção da semelhança da música com a linguagem na nova música se constitui em sentido específico, uma vez que, conforme defenderemos a seguir, a análise adorniana desta questão nos permite falar de dois sentidos de semelhança da música com a linguagem: um primeiro sentido vinculado à música tradicional (música tonal) e um segundo, que, por outro lado, diria respeito especificamente à nova música e, portanto, apontaria para a manutenção deste aspecto estrutural nas obras musicais da nova música.

Para defendermos nossa proposta interpretativa, seguiremos o seguinte percurso argumentativo: em primeiro lugar, abordaremos a constituição histórica da relação entre música e linguagem, perpassando por uma análise que se refere a alguns aspectos estruturais da música que teriam sido engendrados pelo processo histórico em questão, como a constituição da relação entre mimesis e racionalidade própria à estrutura da obra musical. Em segundo lugar, analisaremos como se apresenta a semelhança da música com a linguagem ou, mais exatamente, como esta se constitui especificamente em cada um dos âmbitos musicais que nos propomos a analisar, a saber, na música tradicional e na nova música. Por último - levando à cabo nossa proposta interpretativa -, argumentaremos que cada momento histórico-musical em questão constituiria um sentido específico da semelhança da música com a linguagem, que chamaremos respectivamente de primeiro e segundo sentido.

\section{A constituição da relação entre música e linguagem como resultado do processo histórico de racionalização ocidental}

A relação de entrelaçamento entre música e linguagem, que remete tanto ao caráter de linguagem da música (Sprachcharakter der Musik) quanto à semelhança da música com a linguagem (Sprachähnlichkeit der Musik), possui seu fundamento no próprio desenvolvimento da história ocidental, ou, mais exatamente, em função da participação da música no processo histórico geral (geschichtlichen Gesamtprozeß), que fez com ela adquirisse vários aspectos de outras artes, sobretudo a "linguisticização" 
(Versprachlichung) (cf. Adorno, 1997d, p. 129). Com efeito, a relação necessária entre música e linguagem, como mostrou Max Paddison, faz referência tanto ao envolvimento da música no movimento progressivo de racionalização (cf. 1998, p. 78) quanto no processo de sua transição gradual e efetiva à autonomia (cf. idem, p. 74), sendo ambos os processos engendrados historicamente. Adorno descreve tal processo histórico da seguinte forma:

Ora, o caráter de linguagem específico da música consiste na unidade de sua objetivação [Objektivierung] ou, se preferir, na objetificação [Verdinglichung] e subjetivação [Subjektivierung] não excluindo-se mutuamente, mas condicionando-se em seus polos. Desde que a música, como Max Weber demonstrou em sua póstuma sociologia da música, foi integrada ao processo de racionalização da sociedade ocidental, seu caráter de linguagem [Sprachcharakter] ${ }^{4}$ aumentou (Adorno, 1997i, p. $160,161)$.

A partir disso, pode-se notar que a relação entre música e linguagem teria se engendrado em função da música se constituir como 1) mediação (Vermittlung) - necessária entre sujeito e objeto na constituição de sua forma - e, além disso, através de 2) sua participação no processo de crescente racionalização do ocidente.

No que se refere a questão da mediação ${ }^{5}$ na música, Adorno defende - como expressão de seu posicionamento dialético - no texto Vers une musique informelle que "sob o aspecto dessa irredutibilidade a simples fatos, todos os momentos reificados na arte retornam, como condição objetiva ao próprio sujeito: a mediação subjetiva

\footnotetext{
4 Podemos definir o caráter de linguagem da música (Sprachcharakter der Musik) como algo que seria próximo, mas igualmente distinto da semelhança da música com a linguagem (Sprachähnlichkeit der Musik). O caráter de linguagem da música aponta, em suma, para as características e elementos presentes na música que, em última análise, nos permite concebê-la como uma linguagem sui generis. Nesse sentido, podemos dizer que a música em si pode ser considerada como linguagem ao menos por quatro razões: 1) enquanto uma segunda natureza (Zweite Natur) (cf. Adorno, 2011, p. 19) - quando a concebemos do ponto de vista da tonalidade, por exemplo; 2) enquanto uma espécie de idioma dotado de uma gramática própria, que, entre outras coisas, determina como os sons devem ser articulados, conforme podemos ver, por exemplo, no tonalismo e nas respectivas formas musicais derivadas deste sistema de composição; 3 ) através do desenvolvimento histórico de um sistema de convenções de escrita musical que permitiu a realização de seu registro através da notação musical; 4) ainda seria possível dizer que a música é linguagem em função desta ter configurado uma diversidade de estilos, gêneros e formas musicais, que, por sua vez, nos permitiria falarmos em linguagens musicais (no plural), uma vez que estas apresentariam, por assim dizer, diversas "gramáticas", que, em última análise, constituem a especificidade de cada forma musical (por exemplo, a especificidade da forma sonata em comparação à sinfonia, ou - em termos de estilos e/ou gêneros - a singularidade da música clássica diante da música dodecafônica, etc.).

5 Podemos dizer que a mediação seria fundamental para a constituição tanto da semelhança quanto da diferenciação entre música e linguagem, uma vez que se, por um lado, música e linguagem concebem as mediações como constitutivas de sua estrutura, por outro lado, cada uma se relaciona com as mediações de maneira distinta, pois enquanto a linguagem toma as mediações como constitutivas de sua forma na relação que instituem com o significado, mais especificamente a partir dos conceitos, sendo cada um concebido individualmente e, portanto, como "dependentes entre si", a música, ao contrário, se relaciona com as mediações "através da absorção fatal em uma única estrutura coerente que resgata o significado perdido de cada movimento particular" (Adorno, 2018a, p. 40).
} 
parece ser um fator inextinguível da objetivação estética” (Adorno, 2018b, p. 436). Ou seja, nem mera expressão - conforme buscaria defender a tradição romântica em geral, p. ex. - nem mera objetividade - tese defendida pelo formalismo estético, p. ex. - determinam isoladamente o que viria a ser uma obra musical, mas esta, na realidade, se constitui através de um entrelaçamento dialético entre ambas as esferas, isto é, o polo subjetivo e objetivo, que, concebidos conjunta e de mediatamente, constituem a forma musical. Isso, em última análise, nos remete diretamente a um procedimento composicional que se atente e se estruture adequadamente a partir da dialética entre expressão e construção (cf. Adorno, 1997e, p. 188, 189).

Quanto à presença da racionalização na música, entre várias características presentes nas obras musicais que remetem a este fato histórico, podemos mencionar ao menos três destas: que a música, em função de sua estruturação própria, teria uma 1) proximidade com a lógica $a^{6}$ ou, mais precisamente, com "a vontade lógica de dominação" (Adorno, 2018a, p. 39), aspecto que seria diretamente ligado não somente com a semelhança da música com a linguagem, mas também a dois outros aspectos inerentes à música por derivação da semelhança desta com a linguagem, a saber, o 2) estabelecimento de um nexo (Zusammenhang $)^{7}$ e 3) sua participação - ao menos potencial - no processo histórico de dominação da natureza (cf. Adorno, 2011, p. 57).

No entanto, deve-se destacar que a música - assim como toda obra de arte -, de acordo com Adorno, não somente se estrutura a partir do âmbito da racionalidade, mas também preserva traços míticos e anímicos em sua estrutura, inclusive como consequência de sua relação com a linguagem. Segundo Adorno,

no momento linguístico da música também sobrevive a herança do pré-racional, do mágico e do mimético: em razão de sua "linguisticização" [Versprachlichung],

6 "A sequência dos sons está bastante próxima da lógica: existe um certo e um errado" (Adorno, 2018a, p. 35). Tal proximidade com a lógica, por sua vez, pode ser visualizada tanto na concepção que uma obra pode ser bem sucedida (gelungenes Werk) ou não, bem como - assim como na linguagem denotativa - na exigência do nexo ou estrutura musical (musikalischer Zusammenhang). Pois, longe de ser "um mero aglomerado de sons" (Adorno, 2018b, p. 391), pode-se dizer que a música se concebe enquanto uma estrutura dotada de uma organização e racionalidade própria, que ao mesmo tempo que compartilha traços da razão de modo geral, fornece elementos para uma crítica desta, uma vez que "a arte é racionalidade, que critica esta sem se lhe subtrair" (Adorno, 2008, p. 90).

7 Destacaríamos aqui que a posição adorniana nos remete diretamente ao posicionamento de Schoenberg, e isso não somente porque este, assim como Adorno, pressupõe a lógica e o nexo ou coerência (Zusammenhang) como condições para estruturação da forma musical, mas também porque ele teria estabelecido para a música a necessidade de organização através de uma analogia da música em relação à linguagem. De acordo com Schoenberg, "sem organização, a música seria uma massa amorfa, tão ininteligível quanto um ensaio sem pontuação, ou tão desconexa quanto um diálogo que saltasse despropositadamente de um argumento a outro. Os requisitos essenciais para a criação de uma forma compreensível são a lógica e a coerência [Zusammenhang]: a apresentação, o desenvolvimento e a interconexão das ideias devem estar baseados nas relações internas, e as ideias devem ser diferenciadas de acordo com sua importância e função" (Schoenberg, 1996, p. 27, grifos nossos). 
a música se estabeleceu como órgão da imitação [Organ der Nachahmung], mas agora, ao contrário de suas primeiras agitações [Regungen] gestuais-miméticas, é uma imitação subjetivamente mediada e refletida do que se sucede na interioridade humana [menschlichen Innern]. O processo de "linguisticização" da música significa ao mesmo tempo sua transformação em convenção e expressão (Adorno, 1997i, p. 161).

Essa dimensão mimética, que sobrevive em toda obra musical conjuntamente - e em tensão - com os seus aspectos racionais apontam não somente para seu caráter de linguagem sedimentado historicamente, mas também para um outro aspecto inerente à música, a saber, a sedimentação de gestos em sua estrutura, que, por sua vez, remete diretamente à especificidade de sua interpretação. Nesse sentido, Adorno afirmou que a linguagem da música, diferentemente da linguagem denotativa, que se baseia e institui por meio do significado (Bedeutung), se fundaria em gestos (Gesten) (cf. Adorno, 1997b, p. 154), que enquanto tais apontam diretamente para a dimensão mimética da obra, na medida em que se referem diretamente ao movimento corpóreo do sujeito que, no processo de mimesis, são de algum modo transpostos para a obra enquanto um momento constitutivo desta. Dessa maneira, Adorno definirá a mimica - enquanto correlato do gesto - como um aspecto constitutivo da obra:

A música é mimica na medida em que um som musical em si resulta necessariamente de gestos determinados, um jogo determinado da musculatura facial [ein bestimmtes Spiel der Gesichtsmuskulatur]. A música é até certo ponto a objetivação acústica da expressão facial [die akustische Objektivation des Mienenspiels] (Adorno, 2001, p. 237).

Aqui notamos que, na medida em que a presença de gestos na música remete necessariamente aos movimentos corpóreos próprios e necessários à constituição da música, isto é, sua própria execução, entramos no âmbito da interpretação ${ }^{8}$, que, de acordo com sua especificidade na música, também nos remete necessariamente ao conceito de mimesis, pois, de acordo com Adorno, "apenas na práxis mimética (...) é que a música se desvenda; nunca em uma contemplação independente da execução" (2018a, p. 38).

Sendo assim, os aspectos racionais e miméticos da obra musical concebidos conjuntamente e em tensão mostram-se como fundamentais para a compreensão adequada daquela, uma vez que eles seriam elementos constitutivos da obra, inclusive no que diz respeito ao caráter de semelhança e/ou diferenciação da música com a linguagem. A relação entre mimesis e racionalidade na música e na arte de modo geral, aponta, em última análise, para aquilo que Adorno afirmou na Teoria Estética,

8 A interpretação, além disso, aponta para a relação de semelhança, e ao mesmo tempo de diferenciação da música com a linguagem, uma vez que a música, assim como a linguagem, impõe uma exigência de interpretação. De acordo com Adorno, "música e linguagem exigem interpretação em igual medida, porém de maneiras distintas. Interpretar uma linguagem significa entender a linguagem; interpretar música significa fazer música” (cf. Adorno, 2018a, p. 38). 
a saber, para o fato de que: “A aporia da arte, entre a regressão à magia literal ou a transferência do impulso mimético para a racionalidade coisificante, prescreve-lhe sua lei de movimento; tal aporia não pode remover-se” (Adorno, 2008, p. 90).

\section{A semelhança da música com a linguagem na música tradicional e na nova música}

\section{a. Música tradicional}

A tonalidade é, desde seus primórdios, concebida por Adorno como um sistema de convenções e normas de configuração que estruturam as formas musicais da assim chamada música tradicional a partir da delimitação do que seria permitido ou não. Além disso, a tonalidade em seu momento histórico, de acordo com Adorno, apresentava as condições sine qua non para a constituição de uma estrutura musical que, em última análise, garantiam à obra musical da música tradicional sua validade (Geltung) e seu sentido (Sinn). Estes aspectos, enquanto inerentes à constituição de qualquer que seja a obra musical, portanto, não seriam constituídos na música tradicional de outra maneira senão como adequação à "gramática tonal”, ou seja, a um idioma sedimentado definido pela própria tonalidade.

Nesse sentido, o sistema tonal forneceria os indícios para que Adorno o caracterizasse tanto como segunda natureza (cf. 2019, p. 19) quanto em termos de proximidade ou mesmo semelhança com a linguagem, na medida em que ele se apresenta como uma gramática consolidada e sedimentada historicamente e, à maneira da linguagem denotativa, apresentaria, entre outros elementos, uma espécie de sintaxe e semântica própria.

Ressaltar o elemento histórico da tonalidade, por sua vez, mostra-se no contexto de nossa argumentação como de suma importância, para apontar que seu surgimento, bem como seu próprio declínio, estariam necessariamente relacionados com sua natureza histórica. Este destaque, com efeito, também mostra sua centralidade no que se refere à questão da semelhança da música com a linguagem apontada por Adorno, porque esta - em conformidade com nossa proposta interpretativa - se apresenta como distinta em cada momento histórico, o que nos autoriza a falar sobre sentidos distintos da semelhança da música com a linguagem. Estes seriam, por um lado, aquele que remete à semelhança da música com a linguagem no período histórico-musical da música tradicional (música tonal) e, por outro lado, aquele que se refere à nova música.

Em relação a música tradicional, pode-se constatar que a semelhança da música com a linguagem se apresenta fundamentalmente em termos de um idioma previamente dado, ou seja, a partir da organização da forma musical a partir de 
uma gramática que contém os elementos necessários para a sua constituição, tanto do ponto de vista do seu conteúdo quanto de sua forma. Levando em consideração que "muitas vezes o sentido que emerge da música tradicional não vem dela mesma, mas é simples efeito da padronização do idioma” (Adorno, 2018b, p. 435), a semelhança da música com a linguagem na tonalidade, enquanto idioma previamente dado, é concebida, então, como condição para a constituição da estrutura musical (musikalischer Zusammenhang) (cf. Adorno, 1997e, p. 184) e, nesse sentido, igualmente para o próprio sentido e validade das obras da música tradicional.

\section{b. Nova música}

Se o sentido musical e o sucesso de uma composição na música tradicional eram anteriormente fundamentados no sistema tonal, nota-se que, com a crise deste sistema musical iniciada no século XX, ocorreu uma reformulação radical dos critérios para a determinação de sucesso ou fracasso de uma composição musical. Entre diversos posicionamentos diante da composição musical que distinguiria a nova música da música tradicional (tonal) predominante até então, podemos dizer que um destes certamente diz respeito a sua relação com a linguagem ou, mais precisamente, à semelhança da música com a linguagem (Sprachänhlichkeit der Musik).

\section{i. A nova música e a "alergia coletiva ao primado da semelhança com a linguagem"}

A nova música, quando concebida a partir de seu empreendimento crítico em relação à tradição musical representada pelo sistema tonal, é caracterizada em termos gerais a partir de uma aversão radical a este e, por extensão, a qualquer semelhança com a linguagem. Em termos adornianos, poderíamos caracterizar tal postura da nova música enquanto uma "alergia coletiva ao primado da semelhança com a linguagem" (Adorno, 1997f, p. 654); uma aversão generalizada à semelhança da música com a linguagem que pode ser entendida enquanto uma consequência da crítica radical à música tradicional proposta pela nova música.

No que se refere à própria efetividade da ruptura da semelhança da música com a linguagem, podemos dizer que se, por um lado, a nova música teria até certo ponto sido bem-sucedida em abolir esse aspecto da música, por outro lado, ressaltaríamos que a ruptura aqui mencionada teria um sentido específico: trata-se de uma ruptura com a semelhança da música com a linguagem que esteve estritamente associada à tonalidade, ou seja, com a semelhança com a linguagem compreendida como "idioma universal", que concebemos, conforme nossa proposta interpretativa, como primeiro sentido da semelhança da música com a linguagem. A ruptura da nova música com 
a semelhança da música com a linguagem, nesse sentido, não diz respeito a uma abolição completa desta, mas sim a uma ruptura específica, que se apresenta como consequência da crítica da nova música à tonalidade e seus elementos estruturais. Tal ruptura pode ser concebida, em suma, como uma atitude autônoma que romperia com um sistema de normas instituído: "A diferença entre a tonalidade e o material emancipado de hoje", diria Adorno, seria aquela "entre uma linguagem sedimentada por um lado, e de um procedimento alcançado através da vontade consciente da consciência emancipada" (Adorno, 1997h, p. 278).

Esta consciência musical emancipada alcançada pela nova música diante do sistema de normas da tonalidade não surgiu por acaso, mas como expressão do próprio movimento do material musical; a libertação da nova música em relação à linguagem de convenções da tonalidade não seria produto de um arbítrio subjetivo, mas consequência do próprio processo de desenvolvimento do material musical, que na mesma direção que possibilita a instauração de novas formas, também determina o esgotamento de outras, uma vez que "a tendência do material realizase simultaneamente como restrição e expansão” (Hindrichs, 2019, 64). Portanto, a ruptura da nova música em relação à tonalidade - e, consequentemente, com o primeiro sentido da semelhança da música com a linguagem - não seria concebida de outra maneira senão como resultante da atenção dos compositores da Segunda Escola de Viena ao próprio movimento dialético e histórico do material que, por sua vez, determinou o surgimento de novas possibilidades de estruturação da forma musical a partir da consumação da tonalidade.

\section{ii. Consequências da ruptura da semelhança com a linguagem para a nova música}

A ruptura da nova música em relação à semelhança da música com a linguagem referente à música tradicional (primeiro sentido da semelhança da música com a linguagem), mesmo que concebida como consequência do processo de desenvolvimento do próprio material musical, traria algumas dificuldades específicas à música, tanto no que se refere à estruturação de sua objetividade e sentido quanto em termos de sua compreensibilidade. Partindo da constatação de Adorno que "onde ela [a nova música] se afasta da tensão entre música e linguagem, ela é punida" (Adorno, 1997f, p. 654, grifos nossos), podemos mencionar, por exemplo, enquanto uma consequência significativa de tal ruptura, a dificuldade de constituir um nexo estrutural (Strukturzusammenhang) quando não se tem mais como parâmetro um sistema de normas fixo consolidado para estruturação da forma; no caso da música, a tonalidade: 
quanto menos ela [a música] poderia comprometer-se com um idioma universal [allgemeines Idiom], (...) tanto mais insistentemente cada composição foi designada a produzir um nexo estrutural normativo [gesetzmäßigen Strukturzusammenhang] e a construir um microcosmos autossuficiente a partir de si mesma (Adorno, 1997g, p. 128, grifos nossos).

Ou seja, a nova música, em detrimento de sua ruptura com a tonalidade, deve lidar inevitavelmente com uma dificuldade maior para a constituição da forma musical, pois o que anteriormente era garantido de modo a priori pela tonalidade, a saber, a instituição do sentido e validade da obra musical, agora deve ser constituído através da relação do compositor com o movimento histórico-imanente do material. Nessa mesma direção, Adorno constatou que "a razão mais profunda para a dificuldade da objetividade musical [musikalischer Objektivität] a partir do sujeito emancipado é a dissolução [Zerstörung] da semelhança com a linguagem musical [musikalischen Sprachähnlichkeit]" (Adorno, 1997c, p. 625), pois, de modo contrário ao período histórico da tonalidade, "hoje (...) o nexo ou estrutura musical [musikalische Zusammenhang] emerge a partir de sua estruturação específica [spezifischen Gefüge] e não mais é prescrita por um universal evidente [handfest Allgemeinen]" (Adorno, 1997 , p. 185). Com efeito, tendo em vista que o compositor da nova música não pode mais tomar como ponto de partida a gramática circunscrita pela tonalidade, constata-se então que o nexo ou estrutura musical, que, por sua vez, seria necessária à constituição da obra enquanto tal, deve surgir especificamente da estruturação [Gefüge] da obra, que, por sua vez, seria resultante do trabalho do compositor atento ao movimento histórico objetivo, isto é, ao próprio material musical, que não pressupõe mais regras universais para a constituição da forma musical.

No que se refere à questão da dificuldade de compreensibilidade da nova música, podemos apontar que, além do seu divórcio do consumo (cf. Adorno, 1997k, p. 825) presente desde seus primórdios, “a difícil compreensibilidade [Schwerverständlichkeit] da Nova Música" teria como razão fundamental "a força de resistência da tonalidade" (Adorno, p. 1997k, p. 280). Isso significa que o material tonal, mesmo após seu declínio constatado historicamente, continuou a exercer de algum modo influência tanto no nível da composição - o que explicaria, p. ex., o fato de movimentos musicais reacionários como o neoclassicismo proporem um retorno infundado a uma objetividade que desconsidera o sujeito (cf. Adorno, 1997d, p. 131) - quanto na recepção, uma vez que o público, como consequência da insistente influência da tonalidade, sentiria uma inclinação a rejeitar a priori qualquer obra que não se estruture segundo as normas tonais; no caso da nova música, tal rejeição se baseia sobretudo na incompreensão das obras, que é fundamentada, por sua vez, na negligência dos ouvintes às condições para sua compreensão adequada, a saber, a audição estrutural (cf. Adorno, 2017, p. 60). 
No entanto, cabe-nos questionar, ainda que a nova música tenha sido bem sucedida em abolir até certo ponto a semelhança da música com a linguagem, se esta dissolução teria sido completa, e se fosse o caso, se a música, ainda assim, conseguiria constituir-se enquanto nexo de sentido (Sinnzusammenhang), isto é, enquanto obra musical, uma vez que tais características não somente são fundamentais à constituição desta, mas também estiveram até então necessariamente vinculadas ao fato de a música assemelhar-se à linguagem.

\section{iii. A Permanência da semelhança da música com a linguagem na nova música}

Apesar da revolta coletiva da nova música contra a semelhança da música com a linguagem e da consequente abolição desta característica na música - que ocorreu de modo específico e até certo ponto -, é possível constatar que a semelhança da música com a linguagem se manteve na nova música e, mais do que isso, que ela continuou a ser a condição do sucesso da composição musical. Isso seria constatável ao levar-se em consideração ao menos três aspectos fundamentais: 1) que a música mesmo após o declínio da gramática da tonalidade continuou a se constituir como nexo ou estrutura de sentido (Sinnuzammenhang) e estruturação concreta (konkreten Gefüges) (cf. Adorno, 2018a, p. 35), o que possibilita que a música continue a 2) ser plena de sentido (sinnvoll) (cf. Adorno, 1997a, p. 156, 157) e, por último, 3) o fato de que a objetividade musical é inseparável de sua semelhança com a linguagem (cf. Adorno, 1997f, p. 654). Isso nos revela, em última análise, que Adorno aponta, conforme Cosima Linke teria notado, "para uma semelhança da música com a linguagem constitutiva” (Linke, 2019, p. 165).

No entanto, vale a pena ressaltar que a semelhança com a linguagem aqui referida não diz mais respeito àquela da tonalidade ligada às convenções e a um idioma pré-estabelecido, que chamamos de primeiro sentido, mas sim a outra forma de semelhança com a linguagem, que, inclusive, não remete mais à semelhança com a linguagem ordinária (gewöhnliche Sprache), mas sim ao apontamento de um elemento comum que música e linguagem compartilham, a saber, um nexo ou estrutura de sentido (Sinnzusammenhang). Apesar da partilha deste elemento comum entre linguagem e música, nesta "tal nexo [Zusammenhang] difere do nexo de significação instituído pela linguagem denotativa. O todo realiza-se contra as intenções, integrando-as por meio da negação de cada uma delas" (Adorno, 2018a, p. 40, grifos nossos).

De acordo com Adorno, "ela [a nova música] não se afasta com a semelhança com a linguagem em geral, apenas aquela semelhança reificada [da tonalidade]" (idem, p. 36, 37, grifos nossos). Sendo assim, uma concepção de semelhança da 
música com a linguagem não reificada se afastaria tanto daquela semelhança com a linguagem que diz respeito à tonalidade (convenções) quanto da linguagem ordinária de modo geral, pois a semelhança com a linguagem que é instituída desde a nova música (segundo sentido de semelhança da música com a linguagem) diz respeito à constituição de uma forma musical específica através de uma organização e estruturação própria, que não seja mais baseada em um idioma prévio.

Enquanto a linguagem ordinária aponta para a comunicação (Mitteilung) como parâmetro e finalidade, a nova música não possui como referência o conceito de comunicação, mas, ao contrário, institui-se através de um afastamento deste. Isso fica claro não somente ao levarmos em consideração a constatação de Adorno em Filosofia da Nova Música de que "hoje a emancipação da música é análoga à sua emancipação com relação à linguagem falada e é tal emancipação que resplandece" (Adorno, 2011, p. 103), mas também ao partirmos de sua formulação presente no texto Sobre algumas relações entre música e pintura onde afirma que "a semelhança com a linguagem aumenta com a queda da comunicação" (Adorno, 1997j, p. 633, 634) $)^{9}$. Tal distanciamento do conceito de comunicação vem à tona sobretudo em detrimento de toda arte bem-sucedida criticar a reificação do mundo administrado, e também porque o princípio estruturante da nova música é o da organização como condição para constituição do sentido (cf. Adorno, 1997e, p. 185), que se torna possível, por sua vez, por meio da construção total (Durchkonstruktion) e da forma integral (integrale Gestalt), tendências objetivas na nova música desde Schoenberg (cf. Adorno, 1997b, p. 147).

É possível, finalmente, observar que, apesar do empreendimento crítico com a semelhança com a linguagem, os elementos idiomáticos sempre estiveram presentes na Segunda Escola de Viena (cf. Adorno, 1997c, p. 625), e até mesmo que as formulações mais radicais da nova música decorrem do extremo de sua semelhança com a linguagem (cf. Adorno, 1997f, p. 654, 655). Desse modo, a semelhança da música com a linguagem desde a perspectiva da nova música não somente diz respeito a um princípio distinto da tonalidade, a saber, o da construção total, mas também aponta para a manutenção de um princípio inerente à música como constitutivo de

\footnotetext{
9 A defesa destes posicionamentos nos leva a divergir em parte das interpretações de Ricardo Barbosa e Philip Hogh acerca dos problemas aqui mencionados. Quanto ao posicionamento de Ricardo Barbosa, que teria defendido que "nós emprestamos nossa competência comunicativa às obras de arte" (Barbosa, 2020, p. 45), diríamos, em contraposição, que o princípio regulador da música a partir da perspectiva adorniana não pode ser a comunicação (Mitteilung), sobretudo porque "o conceito de comunicação pertence à indústria cultural” (Adorno, 2018b, p. 438-9). 0 afastamento da comunicação enquanto aspecto central da obra musical bem sucedida, no entanto, não implica - como Philip Hogh defendeu - na constituição de uma música de linguagem privada que "não pode relacionar-se com as sensações do compositor, nem com a realidade extra-musical e nem com a tradição musical, mas somente consigo mesma" (Hogh, 2020, p. 63), pois, ao contrário disso, a música, e mesmo toda obra de arte, teria seu caráter de autonomia necessariamente relacionado ao fato dela ser "fait social", ou seja, fazer uma referência necessária - mesmo que negativa - à realidade empírica e, portanto, à sociedade em geral (cf. p. ex., Adorno, 2008, p. 340).
} 
sua forma, comum a ela e à linguagem: o nexo de sentido (Sinnzusammenhang). A semelhança da música com a linguagem na nova música se constitui então em função de uma mudança de perspectiva perante a relação entre música e linguagem, ou seja, em observação que a mudança de postura da nova música diante da composição se relaciona intrinsecamente ao fato que "hoje a relação entre música e linguagem tornou-se crítica” (Adorno, 2018a, p. 37).

\section{Referências}

Adorno, T. (1997a). Das Altern der neuen Musik. In: . Gesammelte Schriften 14: Dissonanzen. Einleitung in die Musiksoziologie (pp. 143-167). Frankfurt am Main: Suhrkamp Verlag.

Adorno, T. (1997b). Die Funktion des Kontrapunkts in der neuen Musik. In: Gesammelte Schriften 16: Musikalische Schriften I-III (pp. 145-169). Frankfurt am Main: Suhrkamp Verlag.

Adorno, T. (1997c). Form in der neuen Musik. In: - Gesammelte Schriften 16: Musikalische Schriften I-III (pp. 607-627). Frankfurt am Main: Suhrkamp Verlag.

Adorno, T. (1997d). Klassik, Romantik, Neue Musik. In: Gesammelte Schriften 16: Musikalische Schriften I-III (pp. 126-144). Frankfurt am Main: Suhrkamp Verlag.

Adorno, T. (1997e). Kriterien der neuen Musik. In: . Gesammelte Schriften 16: Musikalische Schriften I-III (pp. 170-228). Frankfurt am Main: Suhrkamp Verlag.

Adorno, T. (1997f). Musik, Sprache und ihr Verhältnis im gegenwärtigen Komponieren. In: __. Gesammelte Schriften 16: Musikalische Schriften I-III (pp. 649-664). Frankfurt am Main: Suhrkamp Verlag.

Adorno, T. (1997g). Neue Musik heute. In: Gesammelte Schriften 18: Musikalische Schriften V (pp. 124-133). Frankfurt am Main: Suhrkamp Verlag.

Adorno, T. (1997h). Schiwierigkeiten: II. In der Auffassung neuer Musik. In: Gesammelte Schriften 17: Musikalische Schriften IV (pp. 273-291). Frankfurt am Main: Suhrkamp Verlag.

Adorno, T. (1997i). Über das gegenwärtige Verhältnis von Philosophie und Musik. In: _. Gesammelte Schriften 18: Musikalische Schriften V (pp. 149-176). Frankfurt am Main: Suhrkamp Verlag.

Adorno, T. (1997j). Über einige Relationen zwischen Musik und Malerei. In: Gesammelte Schriften 16: Musikalische Schriften I-III (pp. 628-642). Frankfurt am Main: Suhrkamp Verlag.

Adorno, T. (1997k). Warum ist die neue Kunst so schwer verständlich? In: Gesammelte Schriften 18: Musikalische Schriften V (pp.824-831). Frankfurt am Main: Suhrkamp Verlag.

Adorno, T. (1997l). Zum Verhältnis von Malerei und Musik heute. In: Gesammelte Schriften 18: Musikalische Schriften V (pp. 140-148). Frankfurt am Main: Suhrkamp Verlag.

Adorno, T. (2001). Zu einer Theorie der musikalischen Reproduktion: Aufzeichnungen, ein Entwurf und zwei Schemata. Frankfurt am Main: Suhrkamp. 
Adorno, T. (2008). Teoria Estética. Trad. Artur Morão. Lisboa: Edições 70.

Adorno, T. (2011). Filosofia da Nova Música. Trad. Magda França. São Paulo: Perspectiva.

Adorno, T. (2017). Introdução a Sociologia da Música: doze preleções teóricas. Trad. Fernando R. de Moraes Barros. $2^{a}$ ed. São Paulo: Editora Unesp.

Adorno, T. (2018a). Fragmento sobre Música e Linguagem. In: Quase una Fantasia: Escritos Musicais II (pp. 35-42). Trad. Eduardo Socha. São Paulo: Editora Unesp.

Adorno, T. (2018b). Vers une musique informelle. In: - Quase una Fantasia: Escritos Musicais II (pp. 375-442). Trad. Eduardo Socha. São Paulo: Editora Unesp.

Barbosa, R. (2020). Zur Dialektik von Musik und Sprache: die Sprachähnlichkeit der Musik nach Adorno. Musik \& Ästhetik, Bd 93, 42-57. URL: https://www. musikundaesthetik.de/article/99.120205/mu-24-1-42

Duarte, R. (2014). Sobre o conceito de 'pseudomorfose' em Theodor Adorno. In: - Varia aesthetica: ensaios sobre arte e sociedade (pp. 237-254). Belo Horizonte: Relicário.

Hindrichs, G. (2019). Der Fortschritt des Materials. In: Klein, R.; Kreuzer, J; MüllerDoohm, S. (Orgs.). Adorno-Handbuch (pp. 59-70). $2^{\text {a }}$ ed. Berlin: J.B. Metzler.

Hogh, P. (2020). Sprachähnlichkeit der Musik, Musikähnlichkeit der Sprache: eine Lücke in Adornos Musikästhetik. Musik \& Ästhetik, Bd 93, 58-78. URL: https:// www.musikundaesthetik.de/article/99.120205/mu-24-1-58

Kreis, G. (2019). Der philosophische Kritik der musikalischen Werke. In: Klein, R.; Kreuzer, J; Müller-Doohm, S. (Orgs.). Adorno-Handbuch (pp. 85-96). $2^{\mathrm{a}}$ ed. Berlin: J.B. Metzler.

Linke, C. (2019). Kritik der seriellen Musik. In: Klein, R.; Kreuzer, J; Müller-Doohm, S. (Orgs.). Adorno-Handbuch (pp. 206-213). 2a ed. Berlin: J.B. Metzler.

Paddison, M. (1998). The Language-Character of Music. Some Motifs in Adorno. In: Klein, R.; Mahnkopf, C. (Orgs.). Mit den Ohren denken: Adornos Philosophie der Musik (pp. 71-91). Frankfurt am Main: Suhrkamp.

Schoenberg, A. (1996). Fundamentos da composição musical. Trad. Eduardo Seineman. São Paulo: Editora da Universidade de São Paulo.

Weber, M. (1978). Economy and Society: an outline of interpretative sociology. Ed. Guenther Roth e Claus Wittich. Berkeley, Los Angeles, London: University of California Press.

Esta obra está licenciada com uma Licença Creative Commons Atribuição-NãoComercial-SemDerivações 4.0 Internacional.

https://creativecommons.org/licenses/by-nc-nd/4.0/

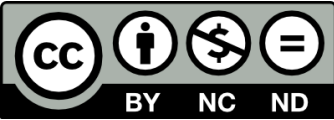

